\title{
Teachers' understanding and use of visual tools in their numeracy classrooms: A case study of two primary schools in Gauteng
}

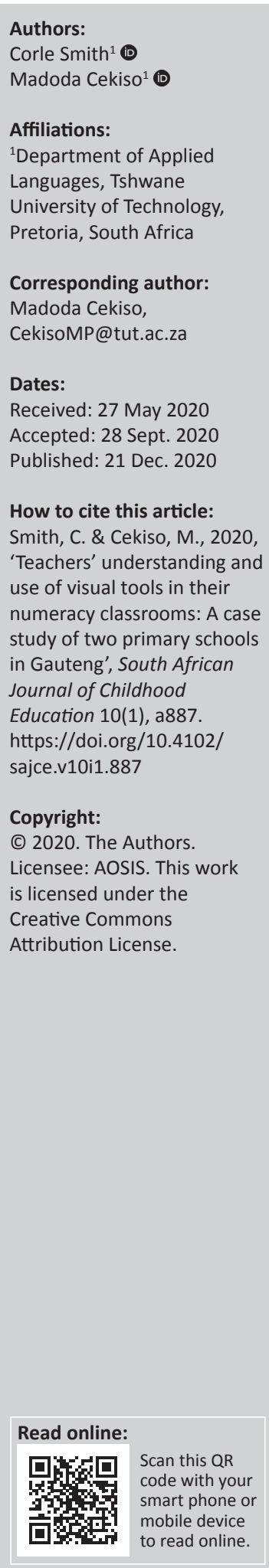

Background: Previous studies have shown the significance of visual objects in facilitating teaching and learning in the numeracy classrooms; however, what we do not know is how South African teachers negotiate the use of visual tools.

Aim: The aim of this study was to explore teachers' understanding and the use of visual tools in their numeracy classrooms.

Setting: This study was conducted in two rural primary schools in Tshwane District, Gauteng. Methods: The study was qualitative in nature and a case study design was followed. Five Foundation Phase teachers were purposively sampled from two primary schools. Open-ended questionnaires were administered to solicit information from the sampled teachers. The collected data were analysed thematically.

Results: The findings revealed that the majority of teachers had a limited knowledge of visual numeracy tools, and as such their implementation was restricted to a few familiar ones. This manifested itself in the fact that the majority of teachers (three out of five) mentioned the general use of the visual tools without clearly relating them to their own classroom experiences. Finally, the findings of the study revealed that all the teachers were desperately in need of training on how to use visual tools in their numeracy classrooms.

Conclusion: The authors concluded that the teachers' limited knowledge about a variety of visual numeracy tools restricted their utilisation of such tools in their classrooms.

Keywords: visual numeracy; pedagogic knowledge; teaching aids; visual tools; early numeracy.

\section{Introduction}

Teaching aids are often discussed in the educational realm where it has become an essential pedagogy for teachers in the process of teaching and learning (Mohamed \& Ahmad 2016). Alshatri et al. (2019) define teaching aids as:

[T] hose accessories, tools and items used by the teachers to assist learners in understanding the concepts of the lesson. The authors further declare that there are many types of teaching aids that go beyond a traditional teaching format. (p. 448)

These include, but are not limited to, visual, audio and audiovisual media. Based on the different types of teaching aids mentioned, this study is about the use of visual aids or tools in numeracy classrooms. The authors define visual tools as physical objects that are designed to represent explicitly and concretely mathematical skills that are abstract. The study pays particular attention to the teachers' understanding and their practical use of the visual tools to teach early numeracy.

The importance of using visual tools is not new in the field of education. Previous studies have shown the significance of visual objects in facilitating teaching and learning in different subjects. Mohamed and Ahmad (2016) focused on the secondary learners' perceptions of the use of visual tools by history teachers and observed that the learners' perceptions were positive and the use of visual tools facilitated their understanding of the history concepts. In another study, King (2018) explored the use of visual objects as tools to understand subject-specific terminologies in life sciences. The results indicated that visual tools helped to facilitate students' understanding of life sciences. These two studies are of different fields and are cited to testify that the use of visual tools facilitates the teaching and learning processes in various subjects. The focus of this 
study is on the use of visual tools in teaching numeracy in the early grades of schooling. The literature reveals that many studies have been conducted to validate the use of the visual tools to enhance numeracy learning (Arcavi 2003; Aunio et al. 2016; Naidoo 2012; Van Garden, Scheuemann, Poch \& Murray 2018; Wilmot \& Schafer 2015; Zodik \& Zaslavsky 2007). The authors of this study believe that visual representation in mathematics involves creating and forming models that reflect mathematical information. Thus, constructing a representation of abstract concepts is likely to facilitate learners' understanding of numeracy concepts.

This study was triggered by complaints raised by Foundation Phase teachers in schools where the study was conducted. The teachers complained about the abstractness of the subject that made it difficult for them to teach. They mentioned that although the instruction was provided in the mother tongue of the learners, as stipulated by the Language in Education Policy, learners still found it difficult to understand the numeracy concepts. This is a cause for concern because numeracy is an essential building block for young children to make a confident start in mathematics (Aunio et al. 2016; Department of Basic Education 2009). As authors, we realised that this was not a problem for the two schools studied, but a general problem in South Africa. For example, Spaull and Kotze (2015) observed poor performance in mathematics of the South African learners who participated in the large-scale assessments. This concern has also been observed by Naidoo (2012), who contended that South African learners show poor performance in mathematics when compared to other countries. Specifically, Howie (2003) stated that South African learners showed extremely poor performance in the Third International Mathematics and Science Study conducted in 1995 and 1999. In addition, Rademeyer (2014) indicated that the results of the Southern and Eastern Africa Consortium for Monitoring Educational Quality showed that, amongst the South African Grade 6 learners who participated in the standardised mathematics test, $80 \%$ of the learners did not perform well.

The poor performance of the South African learners in mathematics has been researched by various scholars, and many factors have been cited as challenges. For example, the Department of Basic Education (2009) declared that:

The National Curriculum Statement for Mathematics with its Learning Outcomes and Assessment Standards describes the knowledge and skills that children should develop through their school career. However, many teachers struggle to translate the curriculum into practice. (p. 126)

This view is supported by Wilmot and Schafer (2015), who found in their study that Grade $R$ teachers lacked the mathematical subject knowledge to use visual tools to teach numeracy. The results of the study conducted by Siyepu (2013) attribute the challenge to socio-economic factors, inadequate qualifications of teachers and the fact that learners study mathematics in a second language. On the contrary, Cope (2015) and Back (2013) blame the teachers' development programme for the lack of effective use of visual tools in their classrooms. This view is supported by Naidoo (2012), who observed that:

$[D]$ espite the fact that research has shown that the use of visual tools in Mathematics classroom is beneficial, but what we do not know is how South African teachers negotiate the use of visual tools (e.g. diagrams, gestures, the use of colour etc.). (p. 1)

To the best knowledge of the researchers, few studies have been conducted in South Africa on the use of visual tools that sought to explore teachers' understanding and use of visual objects in teaching numeracy, amongst which are studies conducted by Wilmont and Schafer (2015) and Mntunjani, Adendorff and Siyepu (2018). Based on these sentiments about the importance of visual tools in teaching numeracy, teachers' understanding and use of visual tools are essential to instruct numeracy in the Foundation Phase. In other words, this article responds to the need for teacher professional development in Foundation Phase numeracy teaching. Therefore, the goal of this study was to provide answers to two research questions.

- What are Foundation Phase teachers' understanding of visual tools to teach numeracy?

- How do Foundation Phase teachers use visual tools to facilitate learners' understanding of numeracy?

\section{Theoretical framework}

Lev Vygotsky's Theory of Cognitive Development was used to anchor this study. Specifically, Vygotsky's zone of proximal development (ZPD) was viewed as the most relevant concept of the theory. According to Vygotsky (1978:86), learners can develop from their actual level to their potential level of development. Vygotsky maintained that a child is able to scaffold onto previous existing knowledge with the assistance of the caregiver. The learner's ZPD as part of his or her inner area of knowledge is changed by interaction with peers and teachers. Vygotsky (1978:86) defined the ZPD as:

[T] he distance between the actual development level as determined by interdependent problem solving and the level of potential development as determined through problem solving under adult guidance or in collaboration with more capable peers. (p. 86)

Wessels (2010) stated that central to the ZPD is the knowledge and abilities that can only be accessed with assistance. Hence, the concept of scaffolding is significant in the ZPD. Teachers should be aware that their duty is to provide learners with the appropriate assistance and tools for them to accomplish the new task or skill. The mathematical skills learners are expected to master in the Foundation Phase include understanding numbers, counting, solving number problems, measuring, sorting, noticing patterns, adding and subtracting numbers and so on. The concept of scaffolding or support is important in Vygotsky's theory. According to Khaliliaqdam (2014:891), the teacher acts as caregiver who should preferably be at a higher level of competence and can influence the learners' development. The caregiver provides knowledge in the form of tools that comprise visuals, graphics and 
collaborative learning. Visuals as part of media can increase the process of mediation and the effectiveness of the ZPD. It is worth noting that the idea of providing the scaffolding is not permanent, but the learners, through practice, acquire the skill and perform independently. In a South African context, numeracy taught in the Foundation Phase is viewed as a springboard for the acquisition of mathematics in the higher grades.

\section{Literature review The role of visual tools in the numeracy classroom}

The authors begin this section by defining numeracy and visual tools. Department of Basic Education and Skills (2011:3) defines numeracy as 'the knowledge, skills, behaviours and dispositions that learners need in order to use mathematics in a wide range of situations'. In other words, it is the ability to access, use, interpret and communicate mathematical information and ideas in various situations. Aunio et al. (2016) drew a distinction between numeracy and mathematics. They argued that a solid foundation in numeracy (Foundation Phase level) facilitates the learners' understanding of mathematics. However, in the context of this study, numeracy and mathematics are used interchangeably. In South Africa, numeracy taught at the Foundation Phase prepares learners for the mathematics lessons they receive in the Intermediate Phase grades and the subsequent higher level grades. According to the Foundation Phase Mathematics Curriculum and Assessment Policy Statement (CAPS), learners' content include numbers, operations and relationships, patterns, functions and algebra, space and shape (geometry), measurement and data handling (statistics). As indicated earlier, the goal of this study was to identify how the teachers understood and incorporated visual tools to facilitate the learners' understanding of the prescribed numeracy content for their grades. Therefore, the subsequent section focuses on the need and use of visual tools in the teaching and learning of numeracy.

\section{The need and use of visual tools}

Shabiralyani et al. (2015) defined visual tools as:

[T] he devices that help the teacher to clarify, establish, and correlate and co-ordinate precise conceptions, understandings and appreciations and support them to make learning more actual, active, motivating, encouraging, significant and glowing. (p. 226)

The research showed that various visual tools such as colour, symbols, pictures, charts, gestures, number line, finger counting, calculation flip boards, number tracks, shape counters, dice, drawings, playing cards, pattern blocks, magnetic numbers and so on have the potential to facilitate numeracy learning. This is because of their power to transform the abstract nature of numeracy to concrete objects. This view was supported by Furner and Worrell (2017) and Arcavi (2003), who argued that mathematics is abstract in nature and as such deals with objects and entities quite different from physical phenomena. Therefore, because of the abstract nature of numeracy observed by these researchers and others, teaching mathematics and numeracy requires the incorporation of visual tools so as to make the abstract nature of mathematics and numeracy concrete.

The importance of the visual tools in the numeracy classroom has been observed by several researchers (Hammill 2010; Raiyan 2016; Van Garderen et al. 2018). For example, Barmby et al. (2017) were of the view that the use of visual tools is an essential part of teachers' knowledge of mathematics that could play an important role in the explanation of mathematical ideas. Zimmermann and Cunningham (1991) declared that 'mathematical visualization is the process of forming images (mentally, or with pencil and paper, or with the aid of technology) and using such images effectively for mathematical discovery and understanding'. Given the importance of visual tools, the critical question many researchers seek to address is how numeracy teachers visualise numeracy and why teachers need visual tools in mathematics? In this regard, researchers like Alshatri, Wakil, Jamal and Bakhtyar (2019) believed that learners usually have difficulties in learning mathematics because of mathematics abstraction; therefore, visualising numeracy has become a solution.

Naidoo (2012) conducted a similar study on master teachers' understanding and use of visual numeracy in KwaZuluNatal, South Africa. Naidoo defined master teachers as experienced teachers who had shown evidence of being able to assist learners to produce good results in the Grade 12 mathematics examination. The findings of the study revealed that each master teacher incorporated the use of visual tools to make mathematical concepts easier to understand for the learners. Specifically:

$[O]$ ne master teacher used a stick with coloured rubber bands to teach rotation about a point, whilst another master teacher used various colours and lines on an interactive smartboard to teach number patterns. The third master teacher used hand gestures to demonstrate the directions of the gradient of a line. (Naidoo 2012:5)

These results clearly indicate that these mathematics teachers knew the value and use of visual tools in assisting the learners grasp abstract concepts. A similar view on the significance of visual tools in facilitating learning in mathematics was expressed by Budaloo (2015), who argued that mathematics is a multimodal discourse where different modes of representation are necessary. This sentiment was supported by the findings of his study that revealed that all the participants in his study were actively engaged in using visual reasoning as a pedagogic practice in their mathematics classrooms. The idea of the different modes of representation highlighted by Budaloo (2015) was supported by Leinhardt et al. (1991), who concluded that the use of multiple representations, in general, is an integral part of teachers' knowledge of mathematics in the explanation of mathematical ideas. 


\section{The importance of developing teachers to teach numeracy}

People's understanding of mathematics and their ability to solve problems are shaped by the teaching they were afforded through their education (National Council of Teachers of Mathematics 2000:148). This serves to emphasise the role of teachers' pedagogic and content knowledge of teaching numeracy and mathematics. Supporting this view, Remillard (2005) stated that teachers' tacit knowledge, professional development and beliefs concerning the teaching and learning of mathematics influence the way they teach mathematics. Venkat and Spaull (2015) also alluded to the fact that one of the problems for the learners' poor performance in mathematics is associated with the teachers' poor knowledge of mathematics. In this regard, the findings of the study conducted by Wilmot and Schafer (2015) revealed that because of the lack of training, Grade R teachers lacked knowledge of how visual arts could be used to teach the concepts of space and shape. To the Foundation Phase teachers' training of teaching numeracy should be added the awareness of how young children learn. Ginsberg and Amid (2008) advised that teachers should be trained to build on the informal mathematical ideas learners bring into the classroom from Day 1. This view is in line with the methodologies of teaching that stipulate that teachers should build from the known to the unknown. In other words, teachers should not underestimate the background knowledge of numeracy learners brought from the informal lessons they acquire from home.

Commenting on the need for teachers' training to teach numeracy, Mntunjani et al. (2018) recommended that teachers should receive the necessary training to use and follow Vygotsky's (1978) ZPD and also make an effort to follow the guidelines indicated in the Curriculum and Assessment Policy Statement (CAPS) (2011) mathematics document. This refers to how and when to incorporate practical mathematics manipulatives or tools. Generally, Vygotsky's ZPD refers to the belief that scaffolding is a key feature of effective teaching where the adult continually adjusts the level of help in response to the learner's level of performance.

In the current study, this refers to the teacher's incorporation of visual tools to support learning in the numeracy classroom so that learners can access the ZPD and concretise the abstract numeracy concepts. Mtetwa $(2005: 255)$ pointed out that it is important for the teachers to understand how and when to use visual tools. This includes teachers' 'understanding that different visual tools serve different functions at different times and in different grades'. Boaler et al. (2016) argued that, as part of teachers' development, teachers should be aware of the common beliefs that visual mathematics is for lower level and for struggling learners. The authors further mention that:

$[L]$ earners who display a preference for visual thinking are often labelled as having special education needs and subsequently, some learners hide their counting on fingers, as they have been led to believe that finger counting is babyish or just wrong. (p. 5)
These are the myths teachers should understand and find a way to deal with. Maybe one of the ways could be an early exposure of all the learners to the visual tools so that they understand that the use of visual tools in numeracy is not reserved for certain individuals. Adding to the importance of teachers' development, Mohamed and Ahmad (2016:3) pointed out that 'the compatibility of teachers in the use of visual tools need to be applied wisely given that it has become a necessity in terms of pedagogy in this century'. This confirms the need for teachers' development to improve their classroom practice in the numeracy classroom.

\section{Research method Design}

This study was qualitative in nature and a case study design was followed. Persuaded by Hyung Lee's (2016) notion that qualitative research is usually concerned with the participants' perspectives and experiences, the research sought to focus on the teachers' understanding and use of visual tools in their numeracy classrooms. Bromley (1990 in Maree 2007:75) defines a case study as 'systematic inquiry into an event or a set of related events which aims to describe and explain the phenomenon of interest'. Therefore, a case study was deemed relevant as it allowed researchers to focus on the subjectivity of the viewpoints and experiences of the Foundation Phase teachers about their understanding and use of visual tools.

\section{Respondents}

The respondents were five Foundation Phase teachers from two schools. These teachers were purposively selected as they were all Foundation Phase teachers from rural schools in Tshwane District, Gauteng. In addition, one of the researchers was the member of the community in which the two schools were located. Therefore, both schools were easily accessible to the researchers because of their proximity. The sample consisted of three black (Grades 1-3) and two mixed race (Grades 1 and 2) female teachers, their ages ranged from 36 to 65 years and their qualifications ranged from diploma to junior degree. Their experiences as Foundation Phase teachers were between 6 and 29 years. In the mixed race school, only two teachers were involved because the Grade 3 teacher was not available at the time the study was conducted; hence, we ended up with five respondents. In the school where the black teachers worked, Setswana, which is the mother tongue of the learners and teachers, was used as a medium of instruction, whereas in the mixed race school, Afrikaans, which is the mother tongue of the learners and teachers, was used as a medium of instruction.

\section{Instrumentation}

A questionnaire designed by the authors was used to collect the data, and it was divided into three sections. Section 1 consisted of the information that required the demographic data of the respondents. Section 2 consisted of open-ended questions. The idea of using open-ended questions was to 
allow the respondents to answer in their own words and elicit more information than would have been possible with a multiple choice format. In addition, through open-ended questions, the researchers hoped to obtain more information and lengthier responses. Specifically, the open-ended questions sought to explore teachers' understanding and use of visual tools to teach numeracy. To achieve this goal, Section 3 of the questionnaire provided a list of 16 visual tools. The list was compiled beforehand after having informal discussions with the Foundation Phase teachers from other schools that were not involved in this study. These teachers were asked about the commonly used visual tools and those that were listed in their textbooks. After the list of visual tools, teachers were asked if there were any other visual tools they used that were not mentioned by the researchers. The list was as follows: diagrams, colour, symbols, pictures, charts, gestures, number line, finger counting, calculation flip boards, number tracks, shape counters, dice, drawings, playing cards, pattern blocks and magnetic numbers. Teachers were asked to indicate the visual tools they were familiar with and to demonstrate how they used them.

\section{Data analysis}

Both researchers read through the data collected. The responses were categorised, and manual coding was performed. We flagged each response with a code. A phrase that summarises the idea was used. Instead of starting with a pre-determined list of codes, both authors went through the responses and allowed the responses to tell them what was significant. Verbatim was used to bring the findings to life.

\section{Ethical consideration}

Ethical clearance to conduct the study was granted by the Tshwane University of Technology by obtaining permission from the Department of Basic Education. These documents were produced to the school principals who later granted permission to one of the researchers to conduct the research at the two identified schools. The participants were informed of their rights to withdraw at any time of the study. They were also ensured that they would stay anonymous in answering all questions pertaining to the role of visuals in teaching numeracy. The participants were given codes (T1, $\mathrm{T} 2$, T3, etc.) to remain anonymous.

\section{Results}

The following subsection provides feedback and analysis of the responses provided by the five Foundation Phase teachers who completed the open-ended questionnaire. The following codes were used to protect the identity of the participants: T1, T2, T3, T4 and T5. The findings that emerged from the interpretation and analysis of the collected data are presented in the following subsections that were guided by the research questions: (1) Foundation Phase teachers' understanding of visual tools to teach numeracy; (2) Foundation Phase teachers' use of visual tools to facilitate learners' understanding of numeracy.

\section{Foundation Phase teachers' understanding of visual tools to teach numeracy}

The first research question focused on the visual tools the teachers used to teach early numeracy. To do that, teachers were provided with a list of visual tools to identify those they were familiar with or used in their classrooms. The list was as follows: diagrams, colour, symbols, pictures, charts, gestures, number line, finger counting, calculation flip boards, number tracks, shape counters, dice, drawings, playing cards, pattern blocks and magnetic numbers. At the end of the list, teachers were asked if there were any other visual tools that they used and were not mentioned in the list. The idea was not to limit the teachers only to the list that was provided by the researchers. In this regard, not a single teacher added to the provided list. Therefore, it was clear that the teachers were only aware of the visual tools that were listed by the authors.

The data collected based on the 16 listed visual tools revealed that only two (T2 and T4) of the five teachers were familiar with all the 16 visual tools. $\mathrm{T} 1$ and $\mathrm{T} 3$ were not familiar with the visual tools listed. The most unfamiliar visual tools were calculation flip books, number tracks, drawings, playing cards, pattern blocks, magnetic numbers and dices. T5 was not familiar with nine visual tools. Therefore, the data showed that only two teachers had an understanding of the various types of visual tools to teach early numeracy. Another theme that emanated from the data is teachers' experiences with using visual tools in teaching numeracy.

\section{Teachers' experiences with using visual tools to teach numeracy}

The second research question was based on teachers' experiences in using various visual tools. Specifically, it required the teachers to explain how they used visual tools to support early numeracy. In this regard, T2 and T4 gave a clear explanation of how they used the 16 visual tools in their numeracy classrooms. For example, T2 demonstrated how she used colour to teach numeracy mentioned:

'I use colour to illustrate e.g. addition. I use blocks of different colours, e.g. 10 red blocks and 5 yellow blocks. This helps learners who learn through experiencing or doing things.' (T2, female, Grade 3)

Demonstrating how she used number line in the numeracy classroom, T2 mentioned:

'I use the number line to teach counting. For example, I omit some numbers and the learners place the missing number. This helps in comparing, rounding, measuring and graphing.' (T2, female, Grade 3)

Responding on how colour is used, T4 said:

'I use colour in the numeracy classroom to create patterns, to indicate e.g. even numbers on the 100-square. I also use it to assist learners to group or distinguish different objects. I also use colour to assist leaners to connect numeracy with the language, for example, "The third colour on the washing line is red".' (T4, female, Grade 2) 
T4 demonstrated her use of number line as follows:

'I use the number line to assist the learners to see clearly what follows and what comes before the continuity is better than a 100-square. Number lines help to show forward and backward counting. It also shows an increase vertically.' (T4, female, Grade 2)

The data further revealed that in some cases, T1, T3 and T5 gave a general use of the visual tools. Sometimes they were not giving their own classroom experiences with the visual tools.

For example, T1 explained how she used the following visual tools: diagrams, colour, symbols, pictures, charts, gestures, number line, finger counting, shape counters and dice. Based on the visual tools that were listed, it was clear that T1 was not using calculation flip books, number tracks, drawings, playing cards, pattern books and magnetic numbers.

Responding to a question about the use of the abovementioned visual tools, T1 responded:

'I am not familiar with these visual tools.' (T1, female, Grade 1)

Similarly, T3 was not using all the listed visual tools. She was familiar with the following: diagrams, colour, symbols, pictures, charts, gestures, number line, finger counting, shape, counters and drawings. It is clear that T3 was not using calculation flip books, number tracks, dice, playing cards, pattern blocks and magnetic numbers.

On the same issue, T5 was using the following visual tools: colour, pictures, gestures, number line, finger counting, dice and pattern blocks. Amongst the five teachers, T5 was using the least number of visual tools. She was not using diagrams, symbols, charts, calculation flip books, number tracks, shape counters, drawings, playing cards and magnetic numbers.

Based on these data, it was evident that T1, T3 and T5 were not using calculation flip books, number tracks, playing cards, pattern blocks and magnetic numbers. This shows that the majority of teachers were not using a wide range of visual tools to assist the numeracy learners.

\section{Teachers' perceptions towards receiving assistance in using visual tools for teaching numeracy}

Although there was no research question on teachers' perceptions towards receiving assistance in using visual tools to teach early numeracy, it was gathered from the teachers' responses that they were desperate for training. The data collected showed that all five teachers needed training. Of interest, and worth noting, is the fact that even teachers like $\mathrm{T} 2$ and $\mathrm{T} 4$, who demonstrated better understanding of visual tools, indicated that they needed training. In this regard, T2 said:

'I need development on how to use visual tools so as to change the perception of numeracy and help learners to see it as exciting subject with real-life application.' (T2, female, Grade 3)
Similarly, T5 mentioned:

'I need development. In fact, what I have observed is that resources are expensive and we rely on parents to buy what learners need. Some parents are battling financially. Therefore, I am also interested in training on how to design visual tools so that I do not depend on the commercial ones.' (T5, female, Grade 1)

The above verbatim quotes demonstrate the teachers' desperation for training on how to use visual tools to improve their classroom practice regarding numeracy teaching. This passion for development is vital as numeracy is a strong foundation for mathematics, which is problematic for South African learners. Therefore, developing the Foundation Phase teachers in numeracy instruction is likely to solve the problem of mathematics at the higher levels.

\section{Discussion of findings}

The research study sought to explore the teachers' understanding and use of visual tools in their numeracy classrooms. The results indicated that the majority of teachers (three out of five) were not familiar with some visual tools listed in the questionnaire. Specifically, the majority of teachers were using diagrams, colour, symbols, pictures, charts, gestures, number line, finger counting, shape counters, dice and drawings. These teachers were not making use of visual tools like calculation flip books, number tracks, playing cards, pattern blocks and magnetic numbers. This finding confirms that the majority of teachers had a poor understanding of the visual tools to teach early numeracy, which is worrying because the use of these visual tools plays an important role in the process of visualising numeracy. This finding explains that some teachers knew a limited number of visual literacy tools. It goes without saying that even their use of visual tools was restricted only to those they identified from the list. This finding confirms earlier research conducted by Wilmot and Schafer (2015), who observed that some mathematics teachers lacked the mathematical subject knowledge to use visual tools to teach numeracy.

The study further sought to examine the Foundation Phase teachers' use of visual tools to facilitate learners' understanding of numeracy. To this end, the results revealed that only two of the five teachers gave a clear explanation of how they used the 16 visual tools in their numeracy classrooms. What has emerged from this study is that the majority of teachers (three of the five) mentioned the general use of the visual tools without clearly relating them to their own classroom experiences. Therefore, there was no clear evidence that they could use some of those visual tools in their classroom because they were not even aware of them. This finding corresponds with Venkat and Spaull's (2015) study that alluded to the fact that one of the problems of the learners' poor performance in mathematics is associated with the teachers' poor knowledge of mathematics.

The finding further supports the studies of Cope (2015) and Back (2013), which put the blame on the teachers' development 
programme for the lack of effective use of visual tools in their classrooms.

This is a sad situation if one takes into consideration the prescripts of the theory on which the study is anchored, that is, Vygotsky's (1978) Theory of Cognitive Development. As mentioned earlier, the teacher is regarded as a knowledgeable person who is supposed to scaffold or support the learners towards the desired goals. The concern emanating from these findings is that how will the teachers fulfil this role given the fact that they are in need of the knowledge and use of the visual tools to teach early numeracy.

Another important finding of this study, which appeared as a secondary finding, is that all the teachers needed training in using visual tools in their numeracy classrooms. Such a reality faced by these teachers is reinforced by Remillard (2005), who stated that teachers' tacit knowledge, professional development and beliefs concerning the teaching and learning of mathematics influence the way in which they teach mathematics. It could so happen that the teachers were aware of the fact that they were not doing enough as far as their use of visual tools in teaching numeracy was concerned. This finding further coincides with that of Ginsberg et al. (2008), who advised that teachers should be trained to build on the informal mathematical ideas learners bring to the classroom from Day 1. The finding on teachers' need for professional development is also in line with Vygotsky's (1978) theory, which was used as the theoretical framework for this study. This theory acknowledges the teacher's ability to provide a learning support to learners. Therefore, without professional development, teachers are not likely to provide the necessary support.

\section{Conclusion}

The aim of this study was to explore the teachers' understanding and use of visual tools in their numeracy classrooms. The findings indicated that the majority of teachers had a poor understanding of the visual tools to teach early numeracy. This manifested itself in the majority of teachers' inability to use a wide range of the visual tools. Moreover, some teachers who claimed to know some visual tools could not convert their knowledge into practice, despite the fact that there are strong links between the use of visual tools and the understanding of numeracy concepts.

With regard to the use of multiple representations or use of a variety of visual numeracy tools in the classroom, the majority of teachers were not familiar with some visual tools listed in the questionnaire. Therefore, it is clear that the teachers' limited knowledge about a variety of visual numeracy tools restricted their use of visual numeracy tools in their classrooms.

The findings also showed that the majority of teachers were not clear about how they used visual numeracy tools in their classrooms. It is worth mentioning that some of them simply gave general information on how visual numeracy tools are used. In other words, these teachers did not reflect on their own experiences about the use of the tools in their numeracy classrooms. This scenario informed our conclusion that some of the teachers were not using these tools as they were expected to do. In fact, this claim is confirmed by the teachers' dire need for training on how to use the visual tools in the classroom. Subsequently, the authors concluded that teachers cannot offer more than they have. In other words, for teachers to be productive, they need to be developed and empowered so that they are in a better position to support the learners.

Although several interesting findings emerged in this study, there are limitations that need to be acknowledged. Apart from the small sample size of this study, the instrument that was used (i.e. open-ended questionnaire) did not allow the authors to make follow-up questions. Another important matter worth mentioning is that, for future studies, it may be beneficial to conduct classroom observations to better understand the teachers' use of the visual numeracy tools. This data collection method (observation) is likely to assist the researchers verify the information provided by teachers in the questionnaire with the actual classroom practice. However, the current study managed to provide insights into the sampled teachers' understanding and use of the visual numeracy tools in the numeracy classrooms.

\section{Acknowledgements}

The authors would like to thank all the teachers who participated in the study.

\section{Competing interests}

The authors have declared that no competing interests exist.

\section{Authors' contributions}

C.S. was responsible for the introduction, collection of data, literature review, data analysis and discussion of findings. M.C. was responsible for conceptualising the title of the manuscript, presenting data and collating the manuscript.

\section{Funding information}

The research received no specific grant from any funding agency in the public, commercial or not-for-profit sectors.

\section{Data availability statement}

Data sharing is not applicable to this article as no new data were created or analysed in this study.

\section{Disclaimer}

The views and opinions expressed in this article are those of the authors and do not necessarily reflect the official policy or position of any affiliated agency of the authors. 


\section{References}

Alshatri, S., Wakil, K., Jamal, K. \& Bakhtya, R., 2019, 'Teaching aids effectiveness in learning mathematics', International Journal of Educational Research Review 4(3), 448-453. https://doi.org/10.24331/ijere.573949

Arcavi, A., 2003, 'The role of visual representation in the learning of Mathematics', Educational Studies in Mathematics 52(3), 215-241. https://doi.org/10. 1023/A:1024312321077

Aunio, P., Mononen, R., Ragpot, L. \& Tormanen, M., 2016, 'Early numeracy performance of South African school beginners', South African Journal of Childhood Education 97, 65-76, 1-14. https://doi.org/10.4102/sajce.v6i.496

Back, J., 2013, Manipulatives in the primary classroom, University of Cambridge, viewed 18 January 2020, from http://nrich.maths.org/10461.

Barmby, P., Bolden, D., Raine, S. \& Thompson, L., 2017, Developing the use of visual representations in the primary classroom, viewed 02 February 2020, from https:// www.nuffieldfoundation.org.

Boaler, J., Chen, L., Williams, C. \& Cordero, M., 2016, 'Seeing as understanding: The importance of visual Mathematics for our brain and learning', Journal of Applied \& Computational Mathematics 5(5), 1-6. https://doi.org/10.4172/2168 9679.1000325

Bromley, D.B., 1990, 'Academic contribution to psychological counselling', Psychology Quarterly 3(3), 299-307.

Budaloo, V.R., 2015, 'The use of visual reasoning by successful mathematics teachers: A case study', Unpublished PhD thesis, University of KwaZulu-Natal, South Africa.

Cope, L., 2015, 'Math manipulations: Making the abstract tangible', Delta Journal of Education 5(1), 10-19.

Curriculum and Assessment Policy Statement (CAPS), 2011, Foundation Phase Mathematics R-3, Department of Basic Education, Republic of South Africa, Mathematic
Pretoria.

Department of Basic Education, 2009, Numeracy handbook for foundation phase teachers-Grades R-3, Department of Basic Education, Pretoria.

Department of Education and Skills, 2011, Literacy and numeracy for learning for life: The national strategy to improve literacy and numeracy among children and young people, Dublin.

Furner, J.M. \& Worrell, N.L., 2017, 'The importance of using manipulatives in teaching Math today', Transformations 3(1), 1-25, viewed from https://nsuworks.nova. edu/transformations/vol13/iss1/2.

Ginsburg, H.P. \& Amit, M., 2008, 'What is teaching mathematics to young children? A theoretical perspective', Journal of Applied Developmental Psychology 29(4), 274-285. https://doi.org/10.1016/j.appdev.2008.04.008

Hammill, L., 2010, 'The interplay of text, symbols, and graphics in Mathematics education', Transformative Dialogues: Teaching \& Learning Journal 3(3), 1-8, viewed 26 July 2019, https://www.kpu.ca/sites/default/files/Teaching.

Howie, S.J., 2003, 'Language and other background factors affecting secondary pupils' performance in Mathematics', Science and Technology Education 22(1), 149-156. performance in Mathematics', Science
https://doi.org/10.1542/pir/2017-0325

Hyung Lee, J., 2016, 'A qualitative inquiry of the lived experiences of music therapists who have survived cancer who are working with medical and hospice patients', Frontiers in Psychology 7, 1840. https://doi.org/10.3389/ hospice patients',
psyg.2016.01840

Khaliliaqdam, S., 2014, 'ZPD, Scaffolding and basic speech development in EFL context', Procedia-Social and Behavioural Sciences 98, 891-897. https://doi. org/10.1016/j.sbspro.2014.03.497

King, C., 2018, 'Exploring the use of visual aids as tools to understanding subject specific terminology in life sciences', Unpublished PhD thesis, University of Stellenbosch, Cape Town.
Leinhardt, G., Putnam, R.T., Stein, M.K. \& Baxter, J., 1991, 'Where subject knowledge matters', in J. Brophy (ed), Advances in research on teaching: Vol. 2. Teachers' matters, in J. Brophy (ed.), Advances in research on teaching: Vol. 2. Teachers' knowledge of subject matte
JAl Press, Greenwich, CT.

Maree, K., 2007, First steps in research, Van Schaik, Pretoria.

Mntunjani, L.M., Adendorff, S.A. \& Siyepu, S.W., 2018, 'Foundation phase teachers' use of manipulatives to teach number concepts: A critical analysis', South African Journal of Childhood Education 8(1), 1-9. https://doi.org/10.4102/sajce.v8i1.495

Mohamed, A.A. \& Ahmad, A.R., 2016, 'Students' perception on the use of visual teaching aids by history teachers and its relationship with students' understanding in the concept of history', The International Journal of Social Sciences and Humanities Invention 3(7), 2389-2396. https://doi.org/10.18535/ijsshi/v3i7.04

Mtetwa, D.K.J., 2005, 'Some characteristics of Mathematics teaching in Zimbabwean infant and primary school classrooms', International Journal of Early Years Education 13(3), 255-264. https://doi.org/10.1080/09669760500295912

Naidoo, J., 2012, 'Teacher reflection: The use of visual tools in mathematics classrooms', Pythagoras 33(1), 1-9. https://doi.org/10.4102/pythagoras.v33i1.54

National Council of Teachers of Mathematics, 2000, Principles and standards for school Mathematics, National Council of Teachers of Mathematics, Reston, VA.

Rademeyer, J., 2014, Is South Africa bottom of the class in Maths and Science? WEF ranking is meaningless, viewed 02 November 2019, from https://africheck.org/ reports.

Raiyan, J., 2016, 'Developing a Mathematics lesson plan based on visual learning technology', I.J. Education and Management Engineering 6(4), 1-9. https://doi. org/10.5815/ijeme.2016.04.01

Remillard, J.T. 2005. 'Examining key concepts in research on teachers' use of Mathematics curricula', Review of Educational Research 75(2), 211-246. https:// doi.org/10.3102/00346543075002211

Shabiralyani, G., Shahzad Hasan, K., Hamad, N. \& Iqbal, N., 2015, 'Impact of visual aids in enhancing the learning process case research: District Dera, Ghazi Khan' Journal of Education \& Practice 6(19), 226-234, viewed 17 June 2020, from https://www.iiste.org.

Siyepu, S.W., 2013, 'The zone of proximal development', South African Journal of Education 33(2), 1-13. https://doi.org/10.15700/saje.v33n2a714

Spaull, N. \& Kotze, J., 2015, 'Starting behind and staying behind in South Africa: The use of insurmountable learning deficits in Mathematics', International Journal of Educational Development 41, 13-24. https://doi.org/10.1016/j.ijedudev. 2015.01.002

Van Garderen, D., Scheuermann, A., Poch, A. \& Murray, M.M., 2018, 'Visual representation in Mathematics: Special education teachers' knowledge and emphasis for instruction', Teacher Education and Special Education 41(1), 7-23. https://doi.org/10.1177/0888406416665448

Venkat, H. \& Spaull, N., 2015, 'What do we know about primary teachers' mathematical content knowledge in South Africa? An analysis of SACMEQ 2007', International Journal of Educational Development 41, 121-130. https://doi.org/10.1016/j. ijedudev.2015.02.002

Vygotsky, L.S., 1978, Mind and society, Harvard University Press, Cambridge, MA.

Wessels, M., 2010, Practical guide to facilitating language learning, Oxford University Press, Oxford.

Wilmot, D. \& Schafer, J., 2015, 'Visual arts and the teaching of the mathematical concepts of shape and space in Grade R classrooms', South African Journal of Childhood Education 5(1), 62-84. https://doi.org/10.4102/sajce.v5i1.350

Zimmerman, W. \& Cunningham, S., 1991, Visualising in teaching and learning mathematics, Mathematical Association of America, Washington, DC, United States.

Zodik, I. \& Zaslavsky, O., 2007, 'Is visual example in Geometry always helpful?' Psychology of Mathematics Education 4, 265-272, viewed 02 February 2020, from https://www.researchgate.net. 